\title{
BIBECHANA
}

A Multidisciplinary Journal of Science, Technology and Mathematics

ISSN 2091-0762 (online)

Journal homepage: http://nepjol.info/index.php/BIBECHANA

\section{Thermo-physical properties of molten Cd-Ga alloys}

\author{
R.P. Koirala ${ }^{1,2}$, B.P. Singh $^{2}$, D. Adhikari ${ }^{1 *}$ \\ ${ }^{1}$ Department of Physics, M.M.A.M. Campus (Tribhuvan University), Biratnagar, Nepal \\ ${ }^{2}$ University Department of Physics, T.M. Bhagalpur University, Bhagalpur, India \\ *Email: adksbdev@yahoo.com
}

Article history: Received 22 June, 2013; Accepted 29 September, 2013

\begin{abstract}
We report thermodynamic, microscopic and surface properties of Cd-Ga alloys in molten state at 700 $\mathrm{K}$. We use quasi-chemical approximation for the computation of thermodynamic and microscopic properties. For the computation of surface we use Butler's approach and quas-chemical approach. We also calculate the surface concentration of the individual component.
\end{abstract}

Keywords: Binary alloys, Entropy of mixing, Short range order, Surface concentration.

\section{Introduction}

The understanding of thermodynamic and surface properties of binary liquid alloys is necessarsy for the design and development of desired materials particularly for high temperature applications. These properties help to know the bonding strength of different species and their local ordering in the alloys. Moreover, information about the mixing properties of solid alloys can be derived from the study of the corresponding initial melts. Liquid alloys are disordered systems in the sense they have no long range order. The complexity in the behaviour of such systems has long been a challenge for researchers in material science and thus determination of thermo-physical properties for alloys in the liquid state is still an active field of research.

Advancement in technology of the alloy systems of non-periodicity in the atomic arrangement has led to an increasing need for a better description of their atomic scale structures. In this paper, we intend to study the thermo-physical properties of Cd-Ga liquid alloy at $700 \mathrm{~K}$. Cadmium containing alloys are generally important for their wide variety of applications as they possess improved mechanical, thermal and electrical properties such as tensile and fatigue strength, hardness, drawability, heat resistance and electrical conductivity etc. Cd-Ga alloy has a characteristic melting point and the liquidus line in the phase diagram is monotectic [1]. It possesses large positive heat of mixing and is characterized by miscibility gaps. This binary segregating liquid alloy has been studied previously using various approaches [1-4]. In the present study we employ the quasi-chemical approximation (QCA) [2,5]for the estimation of the thermodynamic properties such as free energy of mixing $\left(\mathrm{G}_{\mathrm{M}}\right)$, entropy of mixing $\left(\mathrm{S}_{\mathrm{M}}\right)$, heat of mixing $\left(\mathrm{H}_{\mathrm{M}}\right)$ and activity $\left(\mathrm{a}_{\mathrm{i}}\right)$ ); structural properties (concentration fluctuation in the long wavelength limit $\left(\mathrm{S}_{\mathrm{cc}}(0)\right)$, the Warren-Cowley short-range order parameter $\left(\alpha_{1}\right)$ and transport properties (ratio of diffusion coefficients); and statistical formulations for the determination surface properties like surface concentration and surface tension of the Cd-Ga alloy at $700 \mathrm{~K}$. In QCA, a binary liquid A-B alloy is assumed to consist of homo-pairs (A-A and B-B) which are the clusters of like atoms formed by self-association having a short-range interaction. The self- 
associates of types $\mu \mathrm{A}$ and $v \mathrm{~B}$, where $\mu$ and $v$ are the number of atoms in the cluster of types $\mathrm{A}$ and $\mathrm{B}$, respectively, are assumed to be located at their equivalent sites in the alloy [3].

The necessary theoretical formalism is given in Section 2, which follows, results and discussions, and conclusions in Sections 3 and 4, respectively.

\section{Formalism}

Consider one mole of a binary alloy having $\mathrm{Nx}_{\mathrm{A}}$ atoms of element $\mathrm{A}$ and $\mathrm{Nx}_{\mathrm{B}}$ atoms of element $\mathrm{B}$ where $\mathrm{x}_{\mathrm{A}}$ and $\mathrm{x}_{\mathrm{B}}$ represent the mole fraction concentrations of element $\mathrm{A}$ and $\mathrm{B}$. On the basis of this assumption expressions for thermodynamic and microscopic functions have been derived for binary liquid alloys (Singh et al., 1997) as given below.

\subsection{Thermodynamic functions}

The free energy of mixing, $G_{M}$ for binary liquid alloys at temperature $T$ in quasi-chemical approximation can be obtained using the expression [2]:

$$
\begin{aligned}
\mathrm{G}_{\mathrm{M}} & =\mathrm{RT}\left[\mathrm{x}_{\mathrm{A}} \ln \phi+\mathrm{x}_{\mathrm{B}} \ln (1-\phi)\right]+\phi(1-\phi)\left(\mathrm{x}_{\mathrm{A}}+\gamma \mathrm{x}_{\mathrm{B}}\right) \mathrm{W} \\
\text { where } \quad \phi & =\frac{\mathrm{x}_{\mathrm{A}}}{\mathrm{x}_{\mathrm{A}}+\gamma \mathrm{x}_{\mathrm{B}}} ; \quad \gamma=\frac{v}{\mu} \quad \text { and } \quad \mathrm{W}=\mathrm{i} \omega
\end{aligned}
$$

Here $\mathrm{R}$ is universal gas constant; $\mathrm{W}$ is ordering energy parameter and $\omega$ is the interchange energy.

The chemical activities, $\mathrm{a}_{\mathrm{A}}$ and $\mathrm{a}_{\mathrm{B}}$ of constituent elements $\mathrm{A}$ and $\mathrm{B}$ in binary liquid alloys are obtained from the free energy of mixing, $G_{M}$ using following standard thermodynamic relations

$$
R T \ln \mathrm{a}_{\mathrm{A}}=\left(\frac{\partial \mathrm{G}_{\mathrm{M}}}{\partial \mathrm{N}_{1}}\right)_{\mathrm{T}, \mathrm{P}, \mathrm{N}_{2}} ; \quad \mathrm{RT} \ln \mathrm{a}_{\mathrm{B}}=\left(\frac{\partial \mathrm{G}_{\mathrm{M}}}{\partial \mathrm{N}_{2}}\right)_{\mathrm{T}, \mathrm{P}, \mathrm{N}_{1}}
$$

Using Eqs. (1) and (3), the working expressions for the activities are obtained as:

$$
\begin{aligned}
& \ln \mathrm{a}_{\mathrm{A}}=1+\ln \phi-\frac{\phi}{\mathrm{x}_{\mathrm{A}}}+(1-\phi)^{2} \frac{\mathrm{W}}{\mathrm{RT}} \\
& \ln \mathrm{a}_{\mathrm{B}}=\ln (1-\phi)+\phi(1-\gamma)+\gamma \phi^{2} \frac{\mathrm{W}}{\mathrm{RT}}
\end{aligned}
$$

The expression for the entropy of mixing $\left(\mathrm{S}_{\mathrm{M}}\right)$ is derived from the following standard thermodynamic relation:

$$
\mathrm{S}_{\mathrm{M}}=-\left(\frac{\partial \mathrm{G}_{\mathrm{M}}}{\partial \mathrm{T}}\right)_{\mathrm{P}}
$$

Using Eq. (1), $\mathrm{S}_{\mathrm{M}}$ can be obtained as:

$$
\mathrm{S}_{\mathrm{M}}=-\mathrm{R}\left[\mathrm{x}_{\mathrm{A}} \ln \phi+\mathrm{x}_{\mathrm{B}} \ln (1-\phi)\right]-\phi(1-\phi)\left(\mathrm{x}_{\mathrm{A}}+\gamma \mathrm{x}_{\mathrm{B}}\right) \frac{\partial \mathrm{W}}{\partial \mathrm{T}}
$$

Once the free energy of mixing, $G_{M}$ and entropy of mixing, $S_{M}$ are obtained, the heat of mixing, $H_{M}$ can be readily calculated using the standard thermodynamic relation:

$$
\mathrm{H}_{\mathrm{M}}=\mathrm{G}_{\mathrm{M}}+\mathrm{TS}_{\mathrm{M}}
$$

\subsection{Microscopic functions}

The microscopic functions such as concentration fluctuation in long wavelength limit $\left(\mathrm{S}_{\mathrm{CC}}(0)\right)$ and Warren-Cowley [6] short-range order parameter $\left(\alpha_{1}\right)$ are useful properties to obtain valuable information about structure of molten alloys. 


\subsubsection{Concentration fluctuation in long wavelength limit $\left(\mathrm{S}_{\mathrm{CC}}(0)\right)$}

The concentration fluctuation in long wavelength limit $\left(\mathrm{S}_{\mathrm{CC}}(0)\right)$ indicates nature of local ordering of atoms in the liquid alloys. The standard relation for concentration fluctuation in long wavelength limit $\left(\mathrm{S}_{\mathrm{CC}}(0)\right)$ for binary liquid alloys is given as:

$$
\mathrm{S}_{\mathrm{cc}}(0)=\mathrm{RT}\left(\partial^{2} \mathrm{G}_{\mathrm{M}} / \partial \mathrm{x}_{\mathrm{A}}{ }^{2}\right)_{\mathrm{T}, \mathrm{P}}^{-1}
$$

Eqs.(1) and (9) yield:

$$
S_{c c}(0)=\frac{x_{A} x_{B}}{1-x_{A} x_{B} f(\mu, v, \omega)}
$$

where

$$
f(\mu, \nu, \omega)=\frac{2 \frac{W}{R T} \gamma^{2}-(\gamma-1)^{2}\left(x_{A}+\gamma x_{B}\right)}{\left(x_{A}+\gamma x_{B}\right)^{3}}
$$

The value of $\left(\mathrm{S}_{\mathrm{CC}}(0)\right)$ can also be determined using activity data in the following thermodynamic equations:

$$
\mathrm{S}_{\mathrm{cc}}(0)=\mathrm{x}_{\mathrm{B}} \mathrm{a}_{\mathrm{A}}\left(\partial \mathrm{a}_{\mathrm{A}} / \partial \mathrm{x}_{\mathrm{A}}\right)_{\mathrm{T}, \mathrm{P}}^{-1}=\mathrm{x}_{\mathrm{A}} \mathrm{a}_{\mathrm{B}}\left(\partial \mathrm{a}_{\mathrm{B}} / \partial \mathrm{x}_{\mathrm{B}}\right)_{\mathrm{T}, \mathrm{P}}^{-1}
$$

which are usually considered as the experimental values.

\subsubsection{Warren-Cowley short range order parameter $\left(\alpha_{1}\right)$}

In order to quantify the degree of atomic order in the alloy, Warren-Cowley short range order parameter $\left(\alpha_{1}\right)$ for the first nearest neighbours can be estimated from the relation [7]

$$
\alpha_{1}=\frac{\beta-1}{\beta+1}
$$

where $\beta$ is an auxiliary variable given by:

Here $\mathrm{Z}$ represents the number of nearest neighbours of an atom in the bulk, called co-ordination

$$
\beta=\left[1+4 \mathrm{x}_{\mathrm{A}}\left(1-\mathrm{x}_{\mathrm{A}}\right)\left(\eta^{2}-1\right)\right]^{1 / 2}
$$

with

$$
\eta=\exp \left(W / Z k_{B} T\right)
$$
number and $K_{B}$ is Boltzmann number.

In terms of the variable $\beta$, an expression for $\mathrm{S}_{\mathrm{CC}}(0)[7]$ is expressed as

$$
\mathrm{S}_{\mathrm{cc}}(0)=\frac{\mathrm{c}(1-\mathrm{c})}{1+1 / 2 \mathrm{Z}(1 / \beta-1)}
$$

By taking together Eqs. (13) and (16), an expression for $\alpha_{1}$ can be derived in the following form

$$
\alpha_{1}=\frac{(\mathrm{S}-1)}{\mathrm{S}(\mathrm{Z}-1)+1} \quad \text { with } \quad \mathrm{S}=\frac{\mathrm{S}_{\mathrm{cc}}(0)}{\mathrm{S}_{\mathrm{cc}}^{\text {id }}(0)}
$$

where $S_{c c}^{\text {id }}(0)=x_{A} x_{B}$. The value of $\alpha_{1}$ can be computed from the knowledge of $S_{C C}(0)$ using Eq. (17).

\subsubsection{Diffusion}

The mixing behaviour of the alloys forming molten metals can also be studied at the microscopic level in terms of the diffusion coefficients. The $\mathrm{S}_{\mathrm{CC}}(0)$ and diffusion coefficients can be related using Darken thermodynamic equation for diffusion as [8] 


$$
\frac{D_{M}}{D_{\text {id }}}=\frac{S_{c c}^{\text {id }}(0)}{S_{c c}(0)}
$$

where $D_{M}$ is the mutual diffusion coefficient and $D_{i d}$ is the intrinsic diffusion coefficient for an ideal mixture given as:

$$
\mathrm{D}_{\mathrm{M}}=\mathrm{x}_{\mathrm{A}} \mathrm{D}_{\mathrm{B}}+\mathrm{x}_{\mathrm{B}} \mathrm{D}_{\mathrm{A}}
$$

where $\mathrm{D}_{\mathrm{A}}$ and $\mathrm{D}_{\mathrm{B}}$ are the self-diffusivities of pure components $\mathrm{A}$ and $\mathrm{B}$ respectively.

The ratio $D_{M} / D_{\text {id }}$ indicates the mixing behaviour of alloy; $D_{M} / D i d>1$ indicates the tendency for compound formation and $D_{M} / D_{\text {id }}<1$ indicates tendency of segregation. For random mixing, the ratio $\mathrm{D}_{\mathrm{M}} / \mathrm{D}_{\text {id }}$ approaches 1 .

\subsection{Surface properties}

The surface tension effects play vital role in the formation of solid alloys by solidification process of the melts. The knowledge of surface properties is required for understanding of the surface related phenomena such as wetting characteristics of solders, corrosion and kinetics of phase transformation. At high temperatures the surface tension is very sensitive to physical and chemical contamination. Therefore, for understanding, description and metallurgical modeling as well as prediction of structure development during solidification in the binary system surface properties need to be known. The experimental determination of surface tension involves several difficulties in many cases. Because of this, several theoretical models [9-13] have long been developed to determine surface tension data of metals and alloys. In the present paper we employ the following two statistical formulations for the comparative study of the concentration dependence of surface tension of the Cd-Ga liquid alloys at $700 \mathrm{~K}$.

\subsubsection{Butler's Approach}

Butler's formulation for surface tension (Butler, 1932; Koirala et al., 2013) is based on the assumption that the liquid binary mixture has monatomic layer at the surface. This layer is considered as a separate phase that is in thermodynamic equilibrium with the bulk. Under this assumption, the surface tension, $\sigma$ of a binary liquid solution in this approach can be expressed as:

$$
\sigma=\frac{\mu_{1}^{s}-\mu_{1}^{b}}{A_{1}}=\frac{\mu_{2}^{s}-\mu_{2}^{b}}{A_{2}}=\ldots \ldots \ldots . . .=\frac{\mu_{i}^{s}-\mu_{i}^{b}}{A_{i}}
$$

where $\mu_{i}^{s}, \mu_{i}^{b}$ and $A_{i}$ denote the chemical potential of component i in the hypothetical surface, and that in the bulk, and the molar surface area of pure component i respectively. The variation of the chemical potential with the composition of the surface layer in ideal solution can be expressed by the same equation in the surface and in the bulk as follows:

$$
\mu_{i}^{s}=\mu_{i}^{s 0}+R T \ln x_{i}^{s}, \quad \mu_{i}^{b}=\mu_{i}^{b 0}+R T \ln x_{i}^{b}
$$

where $x_{i}^{s}$ and $x_{i}^{b}$ are mole fraction of component $\mathrm{i}$ in the surface, and that in the bulk; $\mathrm{R}$ is the universal gas constant and $\mathrm{T}$ stands for absolute temperature.

From Eqs. (19) and (20), the expressions for the surface tension of the binary alloys can be derived in terms of partial excess free energy of mixing, $G_{i}^{E, b}$ in the bulk and $G_{i}^{E, s}$ at the surface, and surface concentrations, $x_{i}^{b}$ in the bulk and $x_{i}^{s}$ at the surface $(i=A, B)$, in the following forms:

$$
\begin{gathered}
\sigma=\sigma_{1}+\frac{1}{\mathrm{~A}_{1}}\left(\mathrm{G}_{\mathrm{A}}^{\mathrm{E}, \mathrm{s}}-\mathrm{G}_{\mathrm{A}}^{\mathrm{E}, \mathrm{b}}\right)+\frac{\mathrm{RT}}{\mathrm{A}_{1}}\left[\ln \left(\mathrm{x}_{\mathrm{B}}^{\mathrm{s}}\right)-\ln \left(\mathrm{x}_{\mathrm{B}}^{\mathrm{b}}\right)\right] \\
\sigma=\sigma_{2}+\frac{1}{\mathrm{~A}_{2}}\left(\mathrm{G}_{\mathrm{B}}^{\mathrm{E}, \mathrm{s}}-\mathrm{G}_{\mathrm{B}}^{\mathrm{E}, \mathrm{b}}\right)+\frac{\mathrm{RT}}{\mathrm{A}_{2}}\left[\ln \left(\mathrm{x}_{\mathrm{A}}^{\mathrm{s}}\right)-\ln \left(\mathrm{x}_{\mathrm{A}}^{\mathrm{b}}\right)\right]
\end{gathered}
$$


where $\sigma_{1}$ and $\sigma_{2}$ are surface tension of pure component 1 and 2 respectively. $\mathrm{G}_{\mathrm{i}}^{\mathrm{E}, \mathrm{b}}$ and $\mathrm{G}_{\mathrm{i}}^{\mathrm{E}, \mathrm{s}}$ $(i=1,2)$ are partial excess free energy of component $i$ in the bulk and at the surface respectively. The area of monatomic surface layer for the component $\mathrm{i}$ is commonly calculated from the following relation:

$$
\mathrm{A}_{\mathrm{i}}=\mathrm{L} \mathrm{N}^{1 / 3} \mathrm{~V}_{\mathrm{i}}^{2 / 3}
$$

where $\mathrm{L}=1.091$ is called geometrical factor for the closed packed atoms of the surface monolayer. $\mathrm{N}$ is Avogadro's constant and $\mathrm{V}_{\mathrm{i}}$ stands for the molar volume of the component $\mathrm{i}$. The molar volume can be calculated from the atomic mass and density of the pure component.

Solving Eq. (21) and (22) together, we can obtain surface concentration of the components in the liquid solution if the ratio of partial excess free energy in the surface and that in the bulk is known because all other quantities are either known or can be calculated using available data for pure components. Assuming the partial excess Gibbs energy in the bulk and that in the surface to have the same concentration dependence, they can be related to each other through a parameter $\lambda$ as:

$$
\lambda=\frac{G_{i}^{E, s}}{G_{i}^{E, b}}
$$

The value of $\lambda$ is assumed a fixed number in the calculations. In our calculations, we have taken the values of the partial excess free energy in the bulk from the reference [14]

Using of the value of surface concentration in either of Eqs. (21) and (22), surface tension of the binary liquid solution can be computed.

\subsubsection{Quasi-chemical Approach}

The surface tension of regular binary liquid alloys in which no complexes are formed can be examined by the application of quasi-lattice theory [12]. The following pair of equations are available for the theoretical investigation of the surface tension of the binary liquid alloys:

$$
\begin{aligned}
& \sigma=\sigma_{1}+\frac{\mathrm{k}_{\mathrm{B}} \mathrm{T}(2-\mathrm{pZ})}{2 \alpha} \ln \frac{\mathrm{x}_{\mathrm{A}}^{\mathrm{s}}}{\mathrm{x}_{\mathrm{A}}}+\frac{\mathrm{Zk}_{\mathrm{B}} \mathrm{T}}{2 \alpha}\left[\mathrm{p} \ln \frac{\left(\beta^{\mathrm{s}}-1+2 \mathrm{x}_{\mathrm{A}}^{\mathrm{s}}\right)(1+\beta)}{\left(\beta-1+2 \mathrm{x}_{\mathrm{A}}\right)\left(1+\beta^{\mathrm{s}}\right)}-\mathrm{q} \ln \frac{\left(\beta-1+2 \mathrm{x}_{\mathrm{A}}\right)}{(1+\beta) \mathrm{x}_{\mathrm{A}}}\right] \\
& \sigma=\sigma_{2}+\frac{\mathrm{k}_{\mathrm{B}} \mathrm{T}(2-\mathrm{pZ})}{2 \alpha} \ln \frac{\left(1-\mathrm{x}_{\mathrm{A}}^{\mathrm{S}}\right)}{\left(1-\mathrm{x}_{\mathrm{A}}\right)}+\frac{\mathrm{Zk}_{\mathrm{B}} \mathrm{T}}{2 \alpha}\left[\mathrm{p} \ln \frac{\left(\beta^{\mathrm{s}}+1-2 \mathrm{x}_{\mathrm{A}}^{\mathrm{s}}\right)(1+\beta)}{\left(\beta+1-2 \mathrm{x}_{\mathrm{A}}\right)\left(1+\beta^{\mathrm{s}}\right)}-\mathrm{q} \ln \frac{\left(\beta+1-2 \mathrm{x}_{\mathrm{A}}\right)}{(1+\beta)\left(1-\mathrm{x}_{\mathrm{A}}\right)}\right]
\end{aligned}
$$

Here $\sigma, \sigma_{1}$ and $\sigma_{2}$ are surface tensions of alloy and those of pure components $\mathrm{A}$ and $\mathrm{B}$ respectively; $\mathrm{k}_{\mathrm{B}}$ stands for Boltzmann constant; $\mathrm{Z}$ is co-ordination number in the bulk; $\mathrm{x}_{\mathrm{A}}^{\mathrm{s}}$ is the mole concentration of the alloy component $\mathrm{A}$ at the surface. $\alpha$ is the mean atomic surface area given as

$$
\alpha=\sum \mathrm{x}_{\mathrm{i}} \alpha_{\mathrm{i}} \quad(i=1,2)
$$

where the atomic area of hypothetical surface for each component is calculated as:

$$
\alpha_{i}=1.102 N^{-2 / 3} \Omega_{i}^{2 / 3}
$$

where $\Omega_{i}$ is the molar volume of species i and $\mathrm{N}$ stands for Avogadro's number. $\mathrm{p}$ and $\mathrm{q}$ are surface coordination fractions which are defined as the fractions of the total number of nearest neighbours made by atom within its own layer and that in the adjoining layer. For $\mathrm{p}$ and $\mathrm{q}$ the following relation is available (Prasad et al., 1994):

$$
p+2 q=1
$$

and for closed packed structures the values of these parameters are taken as 0.5 and 0.25 respectively. When the disordered structure and relaxation effect of the surface layer are taken into account, $\mathrm{p}$ and $\mathrm{q}$ must be treated as parameters.

The concentration dependent auxiliary variable $\beta$ is defined by the order energy term, $\mathrm{W}$ through the following equation [13] 


$$
\beta=\left[4 \mathrm{x}_{\mathrm{A}}\left(1-\mathrm{x}_{\mathrm{A}}\right) \exp \left(2 \mathrm{~W} / \mathrm{Zk}_{\mathrm{B}} \mathrm{T}\right)+\left(1-2 \mathrm{x}_{\mathrm{A}}\right)^{2}\right]^{1 / 2}
$$

The function $\beta^{\mathrm{s}}$ for surface is obtained from Eq. (28) by replacing the bulk concentration $\mathrm{x}_{\mathrm{A}}$ by the surface concentration $\mathrm{x}_{\mathrm{A}}^{\mathrm{s}}$ and the coordination number $\mathrm{Z}$ by coordination number of the surface atoms, $Z^{s}$. The value of $Z^{s}$ is calculated from its relation with $Z$ given by [13]

$$
Z^{s}=(p+q) Z
$$

\section{Results and discussion}

\subsection{Thermodynamic functions}

In QCA the ratio of self-associates, $\gamma$ and the interaction energy parameter, $\mathrm{W}$ are required for the computation of the thermodynamic and structural properties. These are estimated from Eq. (1) by fitting them into the experimental values of the free energy of mixing and chemical activities at all concentrations [15]. The best fit values of these parameters Cd-Ga liquid alloys at $1023 \mathrm{~K}$ are found to be $\gamma=0.99$ and $\mathrm{W}=+1.9 \mathrm{RT}$.

The free energy of mixing, $\mathrm{G}_{\mathrm{M}}$ computed from Eq. (1) is found negative throughout the entire concentration range and is almost symmetric about equi-atomic composition. The computed values of free energy of mixing have been found in fairly good agreement with the observed values [15](Fig. 1).

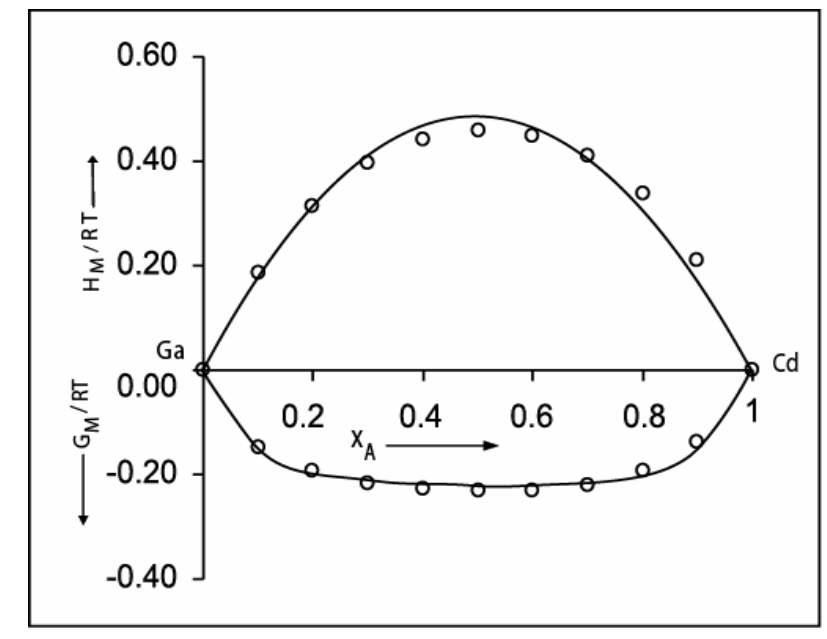

Fig. 1: Free energy of mixing $\left(\mathrm{G}_{\mathrm{M}}\right)$ and heat of mixing $\left(\mathrm{H}_{\mathrm{M}}\right)$ Vs bulk concentration of $\mathrm{C} \mathrm{d}\left(\mathrm{x}_{\mathrm{A}}\right)$ in $\mathrm{Cd}$ Ga liquid alloys at 700K: Theory- solid line ; Experiment- circles.

The interaction energy parameter is assumed to be temperature dependent in QCA for the computation of the entropy of mixing, $\mathrm{S}_{\mathrm{M}}$. The temperature dependence of energy parameter, $\mathrm{dW} / \mathrm{dT}$ has been best estimated from Eq. (7) for the Cd-Ga alloy system at $700 \mathrm{~K}$ to be $\frac{\mathrm{dW}}{\mathrm{dT}}=-0.18 \mathrm{R}$ and the calculated values of entropy of mixing have been found positive at all concentrations. This indicates that there is low ordering of atoms in the Cd-Ga system at the temperature of investigation. A good agreement is observed between theoretical and experimental values [15] (Fig.2). Next the heat of mixing of the Cd-Ga liquid alloy was calculated using the calculated values of free energy of mixing and entropy of mixing in Eq. (8). The calculated values are in reasonable agreement with the observed values [15] (Fig. 1) with small deviation from the experimental values. The deviation may 
be due to the neglect of vibrational and electronic contributions on entropy of mixing. Both calculated and observed values are all positive for the whole range of concentration. This indicates that the alloy system at $700 \mathrm{~K}$ is segregating in nature which is consistent with the sign of ordering energy $\mathrm{W}$. The enthalpic and entropic effects compete with each other to dictate the degree of segregation in the binary alloy systems.

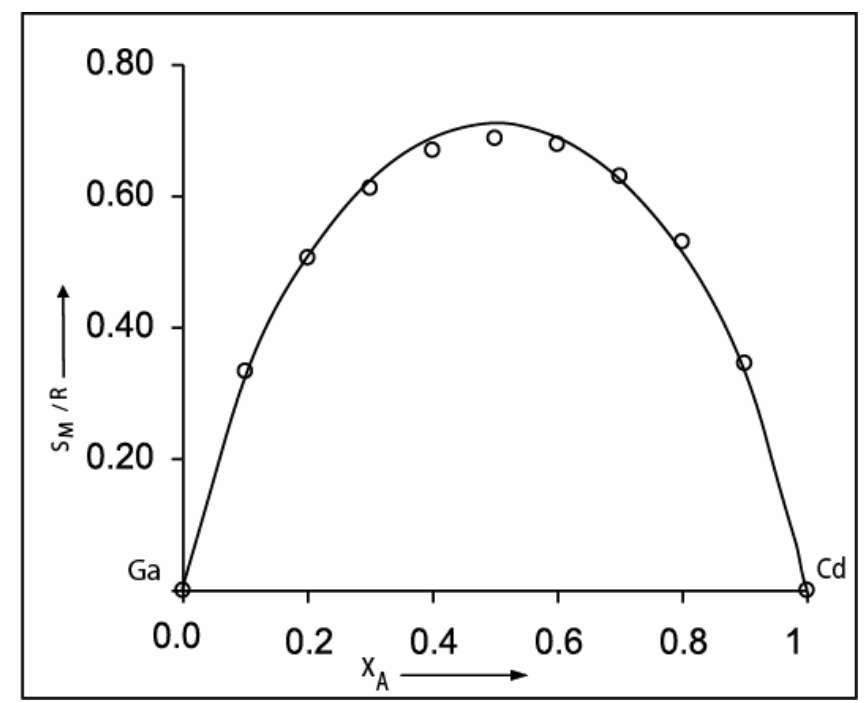

Fig. 2: Entropy of mixing $\left(\mathrm{S}_{\mathrm{M}}\right)$ Vs bulk concentration of $\mathrm{Cd}\left(\mathrm{x}_{\mathrm{A}}\right)$ in $\mathrm{Cd}-\mathrm{Ga}$ liquid alloys at $700 \mathrm{~K}$ : Theory- solid line; Experiment- circles.

The activity is another important thermodynamic function which is a measure of a component to leave the solution. The deviation from the ideal behaviour is incorporated into activity. Activity is used to calculate the values of the concentration fluctuation at long wavelength limit, $S_{c c}(0)$ which are considered as experimental values. The magnitude of the activity depends on the interaction among the constituent species of the system which in turn determine the bond energies. Thus measurement of activity within a class of similar systems can be expected to provide at least a basis for correlation of the behaviour which can be used for the extrapolation of behaviour of more complex systems. In order to maintain the consistency in our calculations, we have used the same values of $\gamma, \mathrm{W}$ and the temperature derivative of $\mathrm{W}$ for the computation of activity. The values of the activities of the component metals calculated using equations (4) and (5) are found in good agreement with the experimental values 15] (Fig. 3).

\subsection{Microscopic functions}

The concentration fluctuation in long wavelength limit $\left(\mathrm{S}_{\mathrm{CC}}(0)\right)$ is an important microscopic function that can be used to understand the nature of atomic order in the binary liquid alloys. When the computed $\mathrm{S}_{\mathrm{cc}}(0)$ is found to be greater than the ideal $\mathrm{S}_{\mathrm{cc}}(0)$ (i.e. $\left.\mathrm{S}_{\mathrm{cc}}(0)<\mathrm{S}_{\mathrm{cc}}^{\mathrm{id}}(0)\right)$ in a binary alloy, then ordering is expected and when $S_{c c}(0)>S_{c c}^{i d}(0)$, tendency of segregation is observed in the alloy. In the present analysis we have found both computed and observed values of $\mathrm{S}_{\mathrm{cc}}(0)$, calculated respectively from Eqs. (9) and (11) greater than ideal values, $S_{\mathrm{cc}}^{\mathrm{id}}(0)$ at all concentrations (Fig. 4). This indicates that there is homo-coordination of atoms in the Cd-Ga molten alloys at $700 \mathrm{~K}$. This result is in well agreement with the result for the heat of mixing. 


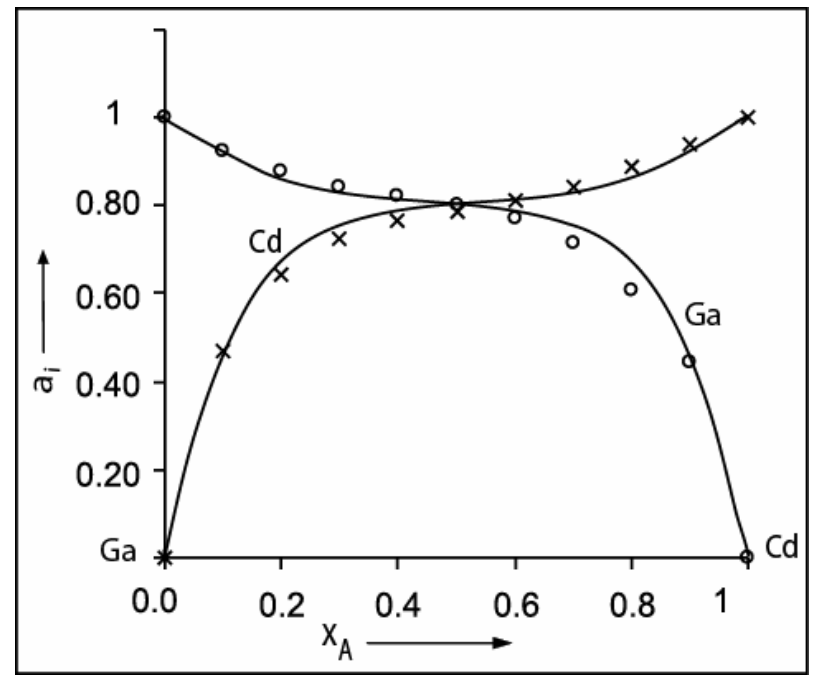

Fig. 3: Activities of $\mathrm{Cd}$ and $\mathrm{Ga}\left(\mathrm{a}_{\mathrm{A}}\right.$ and $\left.\mathrm{a}_{\mathrm{B}}\right)$ bulk concentration of $\mathrm{Cd}\left(\mathrm{x}_{\mathrm{A}}\right)$ in Cd-Ga liquid alloys at 700K: Theory- solid line: Experiment- $\mathrm{a}_{\mathrm{A}}$-crosses; $\mathrm{a}_{\mathrm{B}}$ - circles.

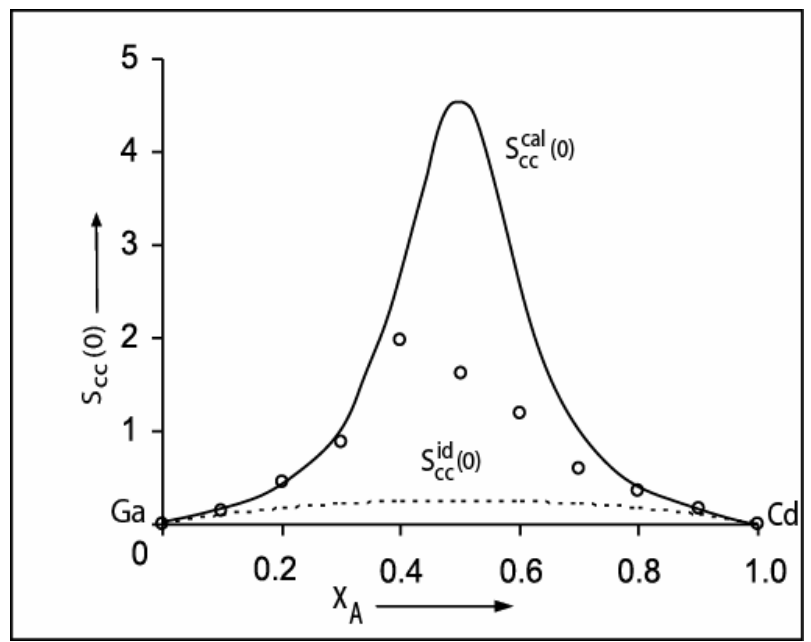

Fig. 4: Concentration fluctuations in long wavelength limit $\left.\left(\mathrm{S}_{\mathrm{CC}}(0)\right)\right) \quad$ Vs bulk concentration of $\mathrm{Cd}$ $\left(\mathrm{x}_{\mathrm{A}}\right)$ in $\mathrm{Cd}-\mathrm{Ga}$ liquid alloys at $700 \mathrm{~K}$ : Theory- solid line ; Experiment- circles; Ideal valuesbroken line.

The Warren-Cowley short range order parameter, $\alpha_{1}$ is another important microscopic function required to get better insight into the degree of local ordering of atoms in the liquid alloys. For a binary liquid alloy if $\alpha_{1}$ is negative, there is tendency of ordering and there is tendency of phase separation if $\alpha_{1}$ is positive. We have calculated the $\alpha_{1}$ using calculated values of $\mathrm{S}_{\mathrm{cc}}(0)$ in the Eq. (17). We have found $\alpha_{1}$ small positive for all concentrations which indicates that there is weak tendency of phase separation in the molten Cd-Ga alloy at $700 \mathrm{~K}$ (Fig. 5), as observed from the results of $\mathrm{H}_{\mathrm{M}}$ and $\mathrm{S}_{\mathrm{cc}}(0)$. In our calculation we have taken $\mathrm{Z}=10$. We note that varying the value of $Z$ does not have any 
effect on the position of minima of $\alpha_{1}$; the effect is to vary the depth while the overall feature remains unchanged.

The other important microscopic function which is required to understand the mixing properties is diffusion. Chemical diffusion coefficient is one of the transport properties which in the present analysis has been calculated from Eq. (18a) and has been found to be positive for the whole range of concentration. Positive values of this ratio indicate that the Cd-Ga liquid alloy at $700 \mathrm{~K}$ is segregating in nature (Fig. 6).

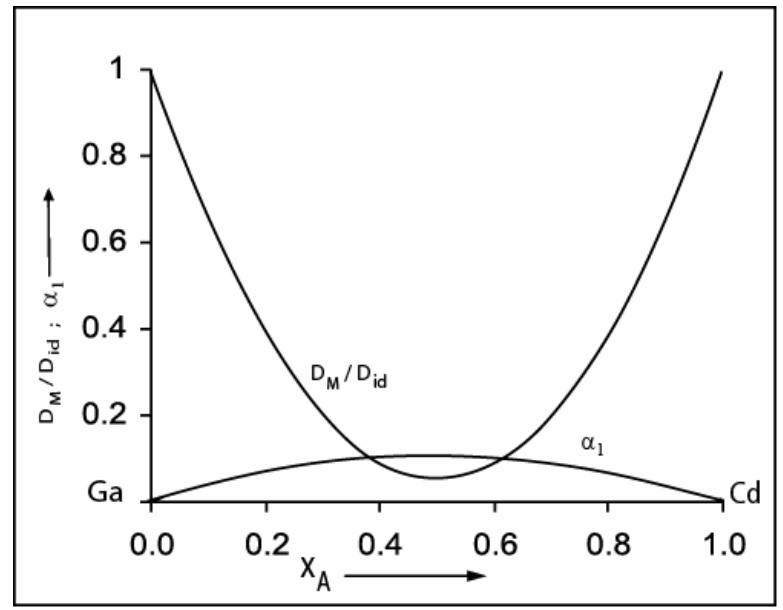

Fig. 5: Ratio of chemical and intrinsic diffusion coefficients $\left(D_{M} / D_{i d}\right)$ and short range order parameter $\left(\alpha_{1}\right)$ Vs bulk concentration of $\mathrm{Cd}\left(\mathrm{x}_{\mathrm{A}}\right)$ in Cd-Ga liquid alloys at $700 \mathrm{~K}$.

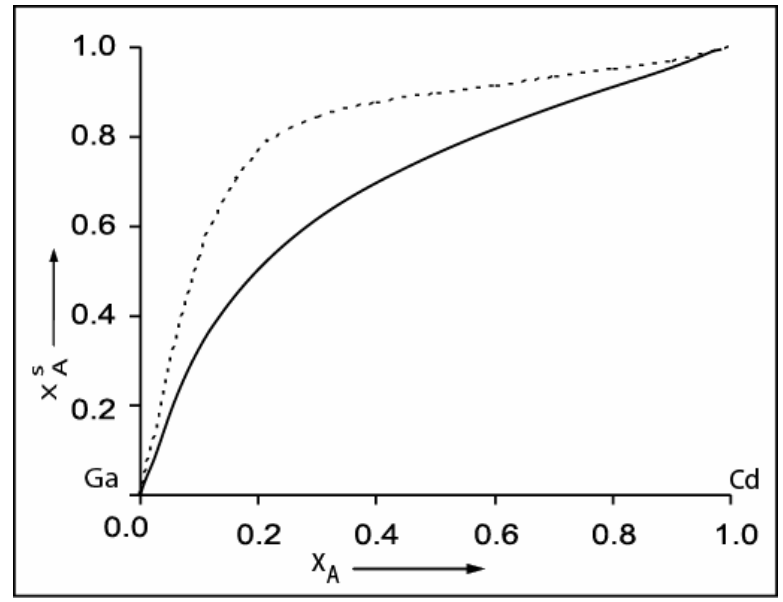

Fig. 6: Surface concentration $\left(\mathrm{x}_{\mathrm{A}}^{\mathrm{s}}\right)$ Vs bulk concentration of $\mathrm{Cd}\left(\mathrm{x}_{\mathrm{A}}\right)$ in Cd-Ga liquid alloys at $700 \mathrm{~K}$ : Butler's approach- solid line; Quasi-chemical approach- broken line.

\subsection{Surface Properties}

\subsection{Butler's approach}

To study the surface properties (surface concentration and surface tension) of the binary liquid alloys from Butler's monolayer approach, we need experimental data of density, surface tension and partial 
excess free energies of mixing of the components at the working temperature. We calculated the density and surface tension for the components $\mathrm{Cd}$ and $\mathrm{Ga}$ at the working temperature by using their temperature coefficients and the values at the melting temperature in the following equations [14]

$$
\begin{aligned}
& \rho(T)=\rho_{m}+\frac{\partial \rho}{\partial T}\left(T-T_{m}\right) \\
& \sigma(T)=\sigma_{m}+\frac{\partial \sigma}{\partial T}\left(T-T_{m}\right)
\end{aligned}
$$

where $\mathrm{T}$ and $\mathrm{Tm}$ are respectively the temperature of investigation and melting temperature; and $\frac{\partial \rho}{\partial \mathrm{T}}$ and $\frac{\partial \sigma}{\partial \mathrm{T}}$ represent the temperature coefficient of density and temperature coefficient of surface tension for each component metal of the alloys.

The partial excess free energies of mixing of the pure components of the Cd-Ga alloys at the temperature of investigation were taken from the ref. [14]. The mole fraction concentration of the Cd-atoms at the surface was then computed at all concentrations by simultaneously solving Eqs. (21) and (22) and then the surface tension of the alloy were worked out from either of these equations. The surface concentration of Cd-atoms is found to have a linear/nonlinear increase with the bulk concentration. The surface tension of the Cd-Ga molten alloys on the other hand is found to decrease with the increasing bulk concentration of the Cd-atoms.

\subsubsection{Quasi-chemical approach}

Mixing properties namely the thermodynamic properties and the surface properties in quasi-chemical approach have an integral relation through the order energy parameter. The surface concentrations of the component metals have been obtained from the simultaneous solution of the Eqs. (25a) and (25b) at all bulk compositions by using the values of the interaction energy parameter obtained from the application of quasi-chemical approximation to the alloys. Surface tension and densities of the components calculated above from Eqs. (31) and (32) were used in solving the equations for surface concentrations. The surface concentration of Cd-atoms in Cd-Ga alloys at $700 \mathrm{~K}$ has been found to be increase with the bulk concentration of the Cd-atoms. When there is a larger difference in surface tension between the solvent and solute, the segregating behaviour of the component is more significant. Having obtained the surface concentrations of Cd-atoms, the surface tension was calculated from either of the Eqs. (25a) or (25b). This approach predicts the surface tension values which are almost matching with those obtained from the previous approach (Fig. 6 \& Fig. 7).

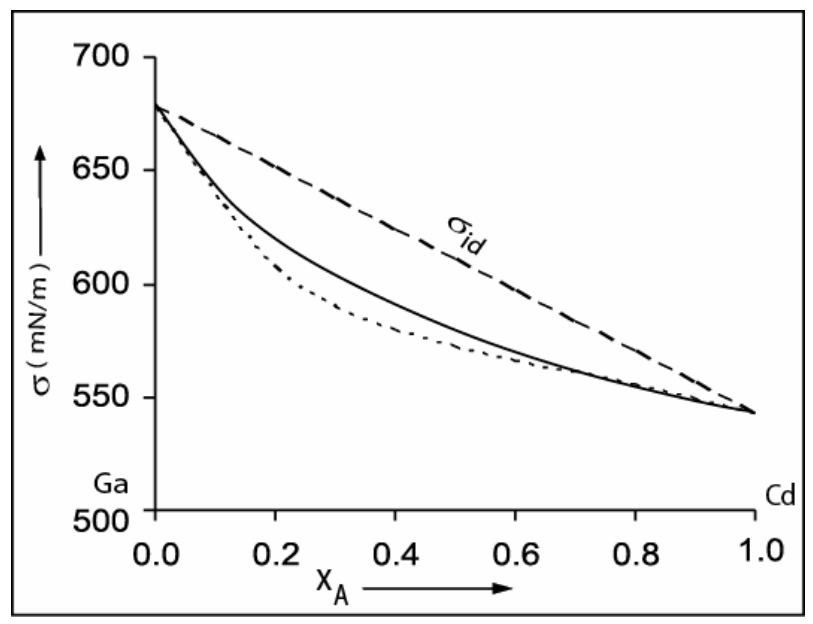

Fig. 7: Surface tension $(\sigma)$ Vs bulk concentration of $\mathrm{Cd}\left(\mathrm{x}_{\mathrm{A}}\right)$ in $\mathrm{Cd}-\mathrm{Ga}$ liquid alloys at 700K: Butler's approach - solid line; Quasi-chemical approach-short broken line; Ideal values - long broken line. 
We do not have experimental values of surface tension of the Cd-Ga alloys at $700 \mathrm{~K}$ to compare our computed result. It is worthwhile to mention that the approaches which we have employed in present work have been successfully used by several workers to compute the surface tension of metallic solution.

\section{Conclusions}

Present theoretical analysis of the microscopic and thermodynamic properties of the Cd-Ga molten alloys at $700 \mathrm{~K}$ reveals that the alloys represent a segregating system; homopairs (Cd-Cd and $\mathrm{Ga}-\mathrm{Ga}$ ) are preferred. The ordering energy is found to be temperature dependent. Furthermore, the study shows that the Cd-component with lower surface tension tends to segregate on the surface of molten alloy while the other component with higher surface tension tends to segregate in the bulk.

\section{Acknowledgements}

We are grateful to Prof. L.N. Jha (Head, Central Department of Physics, T.U., Kathamandu); Prof. P. R. Pradhan (Post-Graduate Department of Physics, M.M.A.M. Campus, T.U., Biratnagar) and Dr. I. S. Jha (Post-Graduate Department of Physics, M.M.A.M. Campus, T.U., Biratnagar) for fruitful suggestions and inspiring discussions.

\section{References}

1. R.N. Singh, I.K. Mishra and V.N. Singh. J.Physics: Condensed Matter, 2(1990) 8457-8462.

2. R.N. Singh and F. Sommer, Rep.Prog. Phys., 60 (1997)57-150.

3. B.C., Anusionwu and C.A. Madu, PRAMANA- J. Physics, 72 (2009) 951-967.

4. A.K. Mishra and M. Milanarun, High temperature materials and Processes, 21 (2005) 47-56.

5. $\quad$ R. N. Singh, Can. J. Phys., 65 (1987)309-325.

6. B.E. Warren, X-ray Diffraction. Addison-Wesley, Reading, 1969.

7. A.B. Bhatia, and R.N. Singh, Physics and Chemistry of Liquids, 13(1984) 177.

8. L.S., Darken, and R.W. Gurry, Physical Chemistry of Metals. McGraw Hill, New York, 1953.

9. J.A. Butler, Proceedings of the Royal Society, A 1932, 135.

10. R.P. Koirala, B.P. Singh,I.S. Jha, and D. Adhikari, Journal of Molecular Liquids, 179(2013) $60-66$.

11. N.H .March and J.A. Alonso Physics and Chemistry of Liquids, 46 (2008)522- 26.

12. R. Novakovic, Journal of Non-Crystalline Solids, 356 (2010) 1593-1598.

13. L.C. Prasad, R.N. Singh and G.P. Singh, Physics and Chemistry of Liquids, 27(1994) 179185.

14. Brandes, Smithells, Metals Reference Book ( Sixth ed.) Sec. 14-6, 1983.

15. R. Hultgren, P. D., Desai, D.T. Hawkins, M. Gleiser and K.K. Kelley, Selected values of the thermodynamic properties of binary alloys, ASM, Metal Park, OH, 1973. 